\title{
Leitura em licenciaturas: a história de leitor de estudantes universitários
}

Deisi Luzia Zanatta*

Fabiane Verardi**

\section{Resumo}

A leitura deve ser uma preocupação em todas as áreas do conhecimento, contudo, os futuros professores de Letras e de Pedagogia atuarão com questões que envolvem a interpretação e a formação do pensamento crítico dos seus alunos. Por isso, neste texto, objetivamos descrever e analisar algum fato, sujeito, objeto, espaço, prática, experiência ou rotina que influenciou na história de leitor de acadêmicos iniciantes em cursos superiores de Letras e de Pedagogia de três universidades brasileiras. Este artigo é resultado de uma pesquisa desenvolvida na Universidade de Passo Fundo (UPF), de 2015 a 2019, que se originou de um Projeto de Cooperação Acadêmica Interinstitucional (Procad), cujas instituições integrantes foram: Universidade Estadual Paulista "Júlio de Mesquita Filho" (Unesp), campi universitários de Assis, de Marília e de Presidente Prudente, Universidade Federal do Espírito Santo (Ufes) e UPF. A análise do resultado evidenciou que diversos elementos como livros, espaços, mídias digitais e sujeitos como pai, mãe, irmão, professor, amigo fizeram parte da história de leitor dos respondentes da pesquisa. Logo, conhecer esse contexto de leitura dos estudantes de Letras e de Pedagogia das instituições que participaram do Procad se torna relevante para conscientizar os docentes universitários dessas licenciaturas para a necessidade de aprimorarem as práticas leitoras durante a formação inicial desses estudantes, futuros professores.

Palavras-chave: Leitura em licenciaturas de Letras e de Pedagogia. História de leitor. Formação inicial de professores. Professor-mediador.
* Doutora em Letras pela Universidade de Passo Fundo (2019). Professora tutora on-line no Núcleo de Educação a Distância (Nead) da Católica de Santa Catarina, Centro Universitário, de Jaraguá do Sul, SC.

** Doutora em Letras (Teoria Literária) pela Pontifícia Universidade Católica do Rio Grande do Sul (2004), com pós-doutorado pela Universidade de Coimbra (2019). Professora titular II da Universidade de Passo Fundo, no curso de Letras e no Programa de Pós-Graduação em Letras, e Coordenadora das Jornadas Literárias de Passo Fundo.

Data de submissão: abril de 2020 - Data de aceite: julho de 2020 http://dx.doi.org/10.5335/rdes.v16i2.10717 


\section{Introdução}

Refletir, investigar e dissertar sobre a formação inicial do professor no que diz respeito à leitura na universidade, especificamente em licenciaturas, são atividades extremamente ambiciosas, mas, ao mesmo tempo, prazerosas. $\mathrm{O}$ estudo que ora se apresenta pode viabilizar a construção de um panorama capaz de explicitar elementos até então implícitos ou desconsiderados em relação à formação leitora de futuros professores.

Roger Chartier (1999, p. 13) postula que "a leitura é sempre uma prática encarnada em gestos, em espaços, em hábitos", que organizam a maneira pela qual os leitores, ao longo do tempo, obtiveram acesso aos livros. Logo, a família, o professor, a biblioteca, a universidade, a internet e o livro podem exercer um papel importante como influenciadores de leitores.

A leitura está presente em toda a sociedade, e, por meio de tal prática, o sujeito amplia seu conhecimento, sua formação pessoal, acadêmica e profissional, bem como o seu senso crítico. Seja de foro íntimo ou público, a leitura "ajuda a elaborar ou manter o sentimento de individualidade, ao qual se liga a capacidade de resistir às adversidades" (PETIT, 2013, p. 67).

Diante disso, este artigo tem por objetivo apresentar e descrever algum fato, sujeito, objeto, espaço, prática, experiên- cia ou rotina que influenciou na história de leitor dos acadêmicos iniciantes em cursos superiores de Letras e de Pedagogia, a partir de dados coletados de um questionário aplicado no ano de 2015/1 a esses acadêmicos nas instituições de ensino superior integrantes do Projeto de Cooperação Acadêmica Interinstitucional (Procad): Universidade Estadual Paulista "Júlio de Mesquita Filho", campi de Assis, de Marília e de Presidente Prudente, Universidade Federal do Espírito Santo (UFES) e Universidade de Passo Fundo (UPF). Para tal, buscamos auxílio teórico em Michèle Petit (2006, 2008, 2013), Roger Chartier (1998, 1999) e Daniel Pennac (1993), sobre a história da leitura e os direitos do leitor; e, acerca do professor como um mediador de leitura, em Regina Zilberman e Ezequiel Theodoro da Silva (1991), Philippe Perrenoud (1999), Paulo Freire (1999) e Lorenzo Tébar (2011).

Eleger a história de leitor dos acadêmicos de Letras e de Pedagogia dessas três universidades brasileiras como objeto de estudo para a discussão no texto que ora apresentamos deve-se à relevância que atribuímos à leitura na formação inicial, ou seja, durante a graduação dos futuros profissionais de Letras e de Pedagogia, que poderão atuar na educação básica, dentre elas a educação infantil, o ensino fundamental II e o ensino médio. Nesse estágio da formação educacional, o pensamento 
crítico precisa ser desenvolvido. Assim, a leitura é uma importante aliada nesse processo, porque é uma atividade inerente à prática docente. Por isso, há a necessidade de um olhar voltado à formação universitária dos respondentes da pesquisa, futuros professores.

Para tanto, além da introdução, este texto está organizado em três seções. $\mathrm{Na}$ primeira, apresentamos a metodologia do estudo; na segunda, algumas considerações sobre a formação inicial de professores e a mediação de leitura; na terceira, a análise dos dados cotejada com a teoria; por fim, seguem as considerações finais.

\section{Metodologia}

O presente trabalho é o resultado de uma pesquisa realizada de 2015 a 2019 na Universidade de Passo Fundo (UPF), estudo esse que, por sua vez, se originou de um desdobramento da pesquisa "Leitura nas licenciaturas: espaços, materialidades e contextos na formação docente", resultado de um Projeto de Cooperação Acadêmica Interinstitucional (Procad), do qual foram integrantes as seguintes instituições de ensino superior: Universidade Estadual Paulista "Júlio de Mesquita Filho", campi de Assis, de Marília e de Presidente Prudente, Universidade Federal do Espírito Santo (Ufes) e Universidade de Passo Fundo (UPF). A finalidade da pesquisa de tal projeto foi descrever e analisar o perfil leitor de universitários ingressantes nas licenciaturas presenciais de Letras e Pedagogia, das referidas instituições, apontando princípios, conhecimentos e ações pedagógicas para a formação de leitores na universidade como espaço privilegiado de mediação da leitura e de circulação de práticas leitoras.

No total, o questionário contou com 85 questões aplicadas aos acadêmicos ingressantes em cursos presenciais de Letras e de Pedagogia, maiores de 18 anos, totalizando 455 sujeitos, das instituições integrantes do Procad no início das atividades acadêmicas de 2015 . Tal instrumento contemplou questões objetivas e discursivas sobre: dados pessoais, tipos de textos lidos habitualmente, o que procura ler e por que motivo, suportes de leitura, espaços de leitura, tempos de leitura, dimensões valorizadas na leitura e indicação de uma preferência específica, que hábitos possui antes, durante e depois da leitura.

$\mathrm{O}$ resultado obtido foi separado nos seguintes blocos temáticos: "Espaços e modos de ler"; "Gêneros textuais"; "Estratégias de leitura"; "Materialidade"; "O papel das instituições e dos mediadores"; e "Suportes de textos". Posteriormente, em uma reunião, as coordenadoras das equipes envolvidas dividiram o conteúdo conforme afinidades com os temas e linhas de pesquisa em que atuavam em suas respectivas universidades. 
Vale enfatizar que tal trabalho englobou três instituições distintas e alicerçadas em contextos diferentes. Contudo, tivemos acesso à soma dos dados de todas as universidades integrantes do projeto, o que permitiu uma visão geral dos resultados do questionário aplicado aos ingressantes de Letras e de Pedagogia. Assim, como não obtivemos as informações nas quais constavam os resultados separados por instituição, não foi possível analisarmos os diferentes contextos e compararmos os produtos. Ressaltamos que tal estudo diz respeito somente aos ingressantes da graduação desses cursos, porque o questionário não foi aplicado aos estudantes concluintes das instituições participantes desse projeto.

Escolhemos, para o presente artigo, a questão 64, por entendermos a importância de conhecermos os elementos que foram relevantes para a história de leitor dos acadêmicos de Letras e de Pedagogia, respondentes da pesquisa, futuros professores.

\section{Formação inicial de professores e a mediação de leitura: alguns apontamentos}

Conforme Regina Zilberman e Ezequiel Theodoro da Silva (1991), a propagação da escola e a valorização da alfabetização enquanto etapa básica e imprescindível do ensino coincidiram com a instalação plena da economia capitalista e da sociedade burguesa. Esta conferiria à educação uma importância aristocrática, legitimando uma postura superior. Já, no contexto burguês, a educação deveria se dirigir indiscriminadamente a todos os segmentos sociais, apresentando-se como fator de democratização e possibilidade de ascensão.

Assim, colocada na base da educação, a leitura pôde assumir de imediato o componente democratizante daquela; ao mesmo tempo, confundiu-se com alfabetização, pois ler veio a significar igualmente a introdução ao universo de sinais conhecidos como alfabeto e a constatação do domínio exercido sobre ele. Com a ascensão do público leitor em meados do século XVIII, a leitura passou a se disseminar mais intensamente na sociedade, ganhando novas proporções.

Diante disso, entendemos que o ambiente escolar é um dos principais espaços onde a leitura deve ser pensada, trabalhada e disseminada, a tal ponto que se torne um hábito entre os estudantes. De acordo com Arnold Hauser (1977), quando a família não possui o hábito de desenvolver a prática leitora, a escola precisa desempenhar esse papel. Sendo assim, tal instituição se torna relevante para a formação de sujeitos, e as práticas nela desenvolvidas são atingidas diretamente pelas diversas transformações que vêm ocorrendo na sociedade ao longo 
do tempo. Isso nos direciona a pensar que é preciso repaginar o método de como as ações que envolvem a leitura são praticadas nesse espaço, uma vez que é por meio de tal ação que realizamos todas as atividades da nossa vida.

A escola possui uma relevância singular na vida das pessoas. Tal lugar pode ser onde ocorrem as primeiras relações sociais dos seres humanos. Nesse ambiente, $o$ aluno convive com os demais colegas e vivencia as mais diversas situações. Assim, fica nítida a função desse espaço: formar o pensamento crítico dos alunos. A leitura, então, torna-se primordial nesse processo, e a incumbência de tão importante tarefa recai nas mãos do professor.

De acordo com Maria Inês Batista Campos (1999), a educação deixou de ser processo presente em atividades sociais e culturais, para adotar o formato da instituição, estrutura, organograma, calendário e orçamento. Eficiente na aparência, o ensino não consegue preencher o ideal que egeu sua criação e continuidade; etimologicamente, "educar" é extrair, levar avante, conduzir para fora e para frente. Nesse sentido, ainda conforme essa estudiosa, é preciso colocar o ideal de ensinar num processo de aprendizagem em que todo aluno será inicialmente reconhecido como potencial leitor.

Conforme Ana Paula Baladeli, Marta Barros e Anair Altoé (2012), a escola, enquanto espaço para disseminação de conhecimento historicamente produ- zido, representa a primeira esfera de contato entre o sujeito e o conhecimento científico. Diante disso, é de sua responsabilidade a adequação de paradigmas, a fim de que possibilite a formação de sujeitos consoantes com a realidade de uma sociedade globalizada.

Vale mencionar que muitas escolas possuem uma infraestrutura adequada, como biblioteca com amplo acervo e salas de leitura confortáveis. Mas de nada isso adianta se não houver um mediador de leitura que viabilize ao aluno o caminho da autonomia nessa prática e na construção de sentidos com base no que lê. Logo, a "formação de leitores em todas as etapas do ensino formal, passa pela mediação do professor" (ROCHA, 2016, p. 55).

Segundo Perrenoud (1999), as sociedades vêm sofrendo mudanças significativas na comunicação, no trabalho, na vida cotidiana e até mesmo nas maneiras de pensar, devido à invasão da tecnologia. Diante disso, esse estudioso enuncia que há de se pensar uma prática reflexiva na formação de professores voltada à inovação e à cooperação, pois tais profissionais "são os mediadores e intérpretes ativos das culturas, dos valores e do saber em transformação" (PERRENOUD, 1999, p. 5). Então, a relevância da leitura para a sociedade contemporânea não deve ser menosprezada.

Assim, o nosso interesse está voltado para a formação do professor como leitor e mediador de leitura, pois sua prática no 
espaço educacional é imprescindível para fundamentar o futuro de seus alunos. Então, a universidade, especialmente nos cursos de licenciaturas de Letras e de Pedagogia, torna-se o espaço de reflexão do pensamento crítico por excelência, uma vez que é nesse espaço que se formam professores. É preciso mais do que a convicção da eficácia das ações desse profissional, ou seja, é necessário fundamentar alicerces sólidos na formação inicial do futuro docente, especialmente no que se refere à leitura. Nessa conjectura, são necessárias práticas leitoras na formação inicial do professor como exercício inerente à sua profissionalização, para que, então, ele se torne leitor e, consequentemente, um mediador, ou seja, uma ponte que liga o aluno aos textos.

Ao voltarmos nossos olhos para o tempo presente, notamos que a era tecnológica trouxe mais velocidade para a vida das pessoas. Diante disso, é preciso analisar e compreender as relações que se encadeiam a cada momento no mundo em que vivemos, e a leitura tende a ser uma aliada nesse processo, já que nos permite interpretar tudo que acontece em nosso entorno. O professor, então, torna-se um profissional importante na vida de seus alunos no que se refere à maneira de pensar e questionar as situações que são vivenciadas no cotidiano, e isso se torna possível através da leitura.

Assim, como um mediador e formador de leitores, tal profissional viabiliza o acesso à cultura e, ao mesmo tempo, expande o conhecimento de mundo dos receptores. Conforme Paulo Freire (1999), as ações docentes são basilares para uma boa formação e contribuem para a construção de sujeitos reflexivos. Diante disso,

[...] o leitor se constrói num processo lento, constante de estímulos e oportunidades de leitura. Essa deve ser a preocupação inicial ao se mediar leitura [...] (SILVA, 2006, p. 78).

A formação leitora e mediadora, então, exige habilidades e competências que os acadêmicos, especialmente de Letras e de Pedagogia, deverão apresentar quando se tornarem professores. Serão necessários conhecimentos de várias esferas do saber, como pensar, planejar, compreender, executar, avaliar, a fim de que as práticas de leitura produzam efeitos no receptor.

Conforme Michèle Petit (2008), o papel do professor como mediador se faz primordial no que se refere a ser um incentivador de livros, isto é, como responsável por iniciar a leitura, legitimá-la, deixar claro o desejo de ler, acompanhando a trajetória do leitor, a fim de construir pontes. Assim,

[...] caberia ao professor um papel radicalmente diferente do que anteriormente exercia: de agente transformador de informações em selecionador dessas informações, seu decodificador, mostrando como descobri-las e selecioná-las e de que maneira transformá-las em saberes (ANTUNES, 2001, p. 12). 
É possível perceber que a leitura é uma prática inerente à profissão docente. Logo, priorizar, na formação inicial do professor, o contato com os textos se torna primordial para que, como profissional, ele saiba mediar a relação dos alunos com os textos. Somente ao repassar o seu hábito pelo prazer de ler e, com isso, desenvolver práticas de leitura que envolvam o contato do sujeito com diversos gêneros e tipologias textuais, será possível a formação de leitores no contexto escolar.

\section{A história de leitor dos acadêmicos de Letras e de Pedagogia: resultado e discussão da pesquisa}

A leitura, nesse sentido, não é somente um passatempo, ou um mecanismo do mundo real e do eu real, como também não se reduz a um meio de adquirir conhecimento. Entendemos que leitura é uma prática em constante uso na nossa vida. Diariamente, estamos lendo tudo o que se encontra em nosso entorno: panfletos, cardápios, livros, etc. A leitura de textos permite que compreendamos os acontecimentos que ocorrem no mundo em que nos inserimos.

O estudioso Paulo Freire (2006) enfatiza que, ao ter de escrever sobre a relevância do ato de ler, precisou reler práticas remotas guardadas na memória que o reportaram para vivências da infância, adolescência, mocidade, ou seja, épocas em que a compreensão crítica da importância da leitura foi se constituindo em sua vida. Ao fazer considerações sobre a sua inserção no mundo da escrita, ressalta que:

[...] a leitura da palavra, da frase, da sentença, jamais significou uma ruptura com a "leitura" do mundo. Com ela, a leitura da palavra foi a leitura da "palavramundo" (FREIRE, 2006, p. 15).

Nesse sentido, a leitura que realizamos do mundo aliada à de textos propicia um alargamento da nossa visão crítica, além de nos reportar a vivências que foram basilares para a nossa constituição como sujeitos. Por isso, a relação do professor com a leitura é de suma relevância, pois, além de introduzir os alunos nessa atividade, deverá orientá-los, indicar obras, a fim de que adquiram diversas experiências, como também expandir as leituras daqueles que já podem ser considerados leitores. Diante disso,

[...] é o meio social que define as ações que serão desempenhadas através de cada instrumento/signo mediador que, por sua vez, favorecerá a construção de conceitos por parte dos indivíduos (de acordo com as possibilidades oferecidas pelo meio) (MOTOYAMA; SANTOS; SILVA, 2017, p. 16).

Conforme Santiago Yubero, Elisa Larrañaga e Pedro Cerrillo (2009), no rastro de toda a história da leitura, os leitores possuem também como elemento comum 
a presença de um leitor que atua como transmissor do gosto pela leitura, que os motiva em muitas ocasiões e compartilha com eles as experiências leitoras. Logo, o professor é um profissional que deve subsidiar e desenvolver atividades de leitura com seus alunos, em suma, dar a ler, como postula Daniel Pennac (1993), a fim de que tal atividade se torne cotidiana e prazerosa na vida desses estudantes.

Michèle Petit (2006) ressalta que a maior parte dos leitores que leem regularmente desde a infância possui outra relação com a leitura do que aqueles que não a praticam. Segundo a estudiosa, o meio social e familiar possui importância singular no incentivo à leitura. $\mathrm{O}$ ato da leitura propicia momentos de busca de uma vida secreta e profunda: dos amores, das emoções, dos mistérios da vida, da morte, da sexualidade. Assim, "a leitura é uma arte que se transmite mais do que ensinada"1 (PETIT, 2006, p. 99, tradução nossa).

Petit (2008, p. 100) assevera que:

A leitura contribui assim para criar um pouco de "jogo" no tabuleiro social, para que os jovens se tornem um pouco mais atores de suas vidas, um pouco mais donos de seus destinos e não somente objetos do discurso dos outros. Ajuda-os a sair dos lugares prescritos, a se diferenciar dos rótulos estigmatizantes que os excluem, e também das expectativas dos pais ou dos amigos, ou mesmo do que cada um deles acreditava, até então, que era o mais adequado para o definir.
A leitura, então, ajuda na constituição da identidade do sujeito. Sendo assim, é inegável a relevância dos mediadores de leitura, pois o ato de ler rompe com os muros existenciais e possibilita a construção do pensamento crítico.

Ao observarmos as respostas da questão discursiva de número 64 do questionário aplicado aos estudantes de Letras e Pedagogia, temos as informações apresentadas no Quadro 1:

Quadro 1 - Cite algum fato, sujeito, objeto, espaço, prática, experiência ou rotina que tenha sido relevante para a sua história de leitor

\begin{tabular}{|l|r|}
\hline $\begin{array}{c}\text { 64. Cite algum fato, sujeito, objeto, } \\
\text { espaço, prática, experiência ou } \\
\text { rotina que tenha sido relevante para } \\
\text { a sua história de leitor. }\end{array}$ & $\begin{array}{r}\text { Frequência/ } \\
\text { Número } \\
\text { de sujeitos } \\
\text { respondentes }\end{array}$ \\
\hline $\begin{array}{l}\text { Membro da família, como pai, mãe, } \\
\text { irmão, irmã, avô, avó, primo, prima, } \\
\text { tio, tia ou amigo }\end{array}$ & 91 \\
\hline $\begin{array}{l}\text { Espaços como casa, biblioteca, es- } \\
\text { cola, sala de aula, espaço religioso, } \\
\text { teatro, universidade }\end{array}$ & 64 \\
\hline $\begin{array}{l}\text { Professor das séries iniciais e finais } \\
\text { do ensino fundamental }\end{array}$ & 73 \\
\hline $\begin{array}{l}\text { A internet, a televisão, filmes, blogs, } \\
\text { sites ou obras como Harry Potter, } \\
\text { Jogos Vorazes e O pequeno príncipe }\end{array}$ & 30 \\
\hline $\begin{array}{l}\text { Interesse próprio, aquisição de co- } \\
\text { nhecimento, curiosidade, gosto, in- } \\
\text { centivo devido a outro curso, fuga } \\
\text { da realidade, compreensão de si e } \\
\text { do mundo, superar perdas de entes } \\
\text { queridos, viajar por mundos desco- } \\
\text { nhecidos, passar o tempo no trans- } \\
\text { porte até a universidade, etc. }\end{array}$ & 83 \\
\hline Não possuem o hábito, não lembram & 4 \\
\hline Em branco & \\
\hline Total & \\
\hline Fonte: Procad. & \\
\hline
\end{tabular}

Fonte: Procad. 
Notamos que, dos 455 sujeitos respondentes que indicaram um fato, sujeito, objeto, espaço, prática, experiência ou rotina que tenha sido relevante para a sua história de leitor, 91 alegaram que foram incentivados a ler por um membro da família, como pai, mãe, irmão, irmã, avô, avó, primo, prima, tio, tia, ou um amigo.

Podemos inferir, a partir dos resultados obtidos, que o gosto pela leitura de boa parte desses acadêmicos de Letras e de Pedagogia é oriundo do berço familiar ou da influência de amigos. Com isso, vale atentar que os membros da família são as primeiras pessoas com as quais nos relacionamos e, com isso, o meio familiar é o primeiro espaço de convivência, bem como o lugar onde adquirimos nossas primeiras experiências.

De acordo com Marisa Lajolo e Regina Zilberman (2003), a história do leitor principiou na Europa por volta do século XVIII, quando a impressão de obras escritas passou a ser exercida por tipógrafos e gerenciada pelo Estado. Com o fortalecimento da escola e da obrigatoriedade do ensino, o público consumidor de livros começou a se expandir, mas somente se tornou uma prática social a partir da valorização da família que construiu e consolidou e sociedade burguesa. Foi nesse meio que o gosto pela leitura se intensificou e passou a ser um exercício próprio da vida moderna. Também, era do interesse dos líderes religiosos que as pessoas soubessem ler, pois, assim, a leitura da Bíblia seria praticada e auxiliaria na formação moral das pessoas.

Diante disso, os membros mais velhos da família influenciaram na formação leitora dos demais integrantes. Bernard Lahire (1997), em um estudo analítico acerca do sucesso escolar de crianças de origem popular francesa, descobriu que a família era a grande responsável pela formação pedagógica, principalmente no que se referia à leitura e à escrita. As crianças oriundas desses lares obtinham um maior sucesso escolar. Logo, para tal estudioso:

Quando a criança conhece, ainda que oralmente, histórias escritas, lidas por seus pais, ela capitaliza - na relação afetiva com seus pais - estruturas textuais que poderá reinvestir em suas leituras ou nos atos de produção escrita. Assim, o texto escrito, o livro, para a criança, faz parte dos instrumentos, das ferramentas cotidianas através das quais recebe o afeto de seus pais. Isto significa que, para ela, afeto e livros não são duas coisas separadas, mas que estão bem associadas (LAHIRE, 1997, p. 20).

Entendemos, então, que a família desempenha um papel importante no processo de introduzir a leitura na vida das crianças, e essa formação leitora será ainda mais produtiva quando aliada às práticas de leitura na escola. Assim,

[...] a ação da escola, da família, do conjunto da vida social tem por finalidade facilitar a construção da criança-leitora e fazer da leitura uma prática cultural costumeira compartilhada por todos (HORELLOU-LAFARGE; SEGRÉ, 2010, p. 82). 
Mesmo que 91 sujeitos tenham mencionado a influência de um membro familiar no incentivo à leitura, a grande maioria dos respondentes alegou ter sido influenciada por outros mediadores. Isso significa que, talvez, em muitos lares, a leitura pode não ser praticada e, por isso, não é incentivada. Tal dado reforça ainda mais a importância da escola no que diz respeito à influência no ato de ler.

Ao ser questionado por Livia Perozim (2009), em uma entrevista para Carta na escola, se várias pesquisas confirmam que a leitura é uma história de família, qual a razão de algumas pessoas praticarem a leitura e outras não, mesmo estando em condições similares na mesma família, Ezequiel Teodoro da Silva menciona que, com o enfraquecimento da instituição familiar na estimulação socioambiental da leitura, a escola ganha uma importância mais acentuada, assumindo a função de formadora de leitores.

A escola, então, pode apresentar a leitura para os sujeitos que não a praticam no meio familiar e, com isso, quem sabe, abrir possibilidade de transformação na vida dessas pessoas. Logo, a leitura através da ação de um mediador pode se tornar um agente de modificação particular e social, na medida em que o indivíduo adentra nas esferas do saber e percebe que há outros vieses para a sua condição.

Seguindo na análise dos resultados da pesquisa do Procad, 64 sujeitos afirmaram que casa, biblioteca, escola, sala de aula, espaço religioso, teatro e universidade foram ambientes primordiais na sua constituição como leitores. Esse dado aponta para a relevância cultural e de acesso ao conhecimento que tais espaços propiciam. Nesse particular, enfatizamos a importância da biblioteca, lugar que foi mencionado pelos sujeitos da pesquisa, como uma esfera singular, que deve ultrapassar a mera definição de depósito de livros e se tornar um ambiente onde se dá o encontro do ser humano com o mundo da leitura.

A biblioteca precisa se tornar um espaço de trocas entre os leitores e o livro. Conforme Chartier (1998), um leitor pode ter prazer ao visitar uma biblioteca pública, com livre acesso às prateleiras, circulando pelo que tal espaço pode oferecer. Já nas bibliotecas de pesquisa, como as existentes na França, o leitor somente encontra os livros que são procurados. Na biblioteca pública, por sua vez, as pessoas encontram livros que não são buscados, como se fossem as obras que procurassem os leitores.

Os postulados do historiador do livro permitem compreender que as diversas bibliotecas existentes, de certa forma, assumem determinadas características, e isso se relaciona com os tipos de leitores que exploram seu acervo. $\mathrm{O}$ ensino superior, então, como lugar de formação, precisa apresentar a biblioteca como um espaço de aquisição cultural, acesso à informação e à leitura. Logo: 
[...] que seja um lugar de mestiçagens, de cozinha de ingredientes globais e locais, onde a constante renovação do mundo encontre um eco palpável através da coleção e, também, um espírito de abertura e de ir até o ambiente, para conhecê-lo, descobri-lo e vinculá-lo com o que sucede em outros lugares e contextos de referência (MÉKIS, 2016, p. 174-175).

Com isso, a biblioteca passa a ser um dos locais basilares para a formação do futuro docente, uma vez que certas atividades de leitura, quando são desenvolvidas nesse ambiente, fazem com que o acadêmico potencialize suas atitudes e competências leitoras: compreender, refletir, inferir e explorar as informações presentes no texto. Esse espaço, assim, torna-se primordial na formação inicial do professor.

Um fato que chama a atenção é que 73 acadêmicos enunciaram o professor como principal influenciador no gosto pela leitura. Esse dado leva a entender que é indiscutível a relevância de tal profissional no processo de formação de leitores. $\mathrm{O}$ professor, nesse sentido, é um profissional que tem a capacidade de transformar a vida de seus alunos por meio da leitura, uma vez que "o homem transforma seus saberes, mas também é influenciado e transformado durante o processo" (MOTOYAMA; SANTOS; SILVA, 2017, p. 29).

Diante desse resultado, percebemos a função importante do professor na sociedade, bem como o poder que tal profissional possui para a formação do pensamento crítico dos sujeitos. Assim, propiciar oportunidades de contato com materiais diversos de leitura que sejam da preferência dos leitores tende a criar um hábito livre de imposições e leituras obrigatórias.

Conforme Horellou-Lafarge e Segré (2010), a relação entre professor e aluno é primordial, pois, uma vez instaurada uma ligação de confiança, o docente consegue transmitir aos estudantes o gosto pela leitura. Os sujeitos oriundos de famílias mais modestas e desprovidas culturalmente podem seguir de bom grado os conselhos do professor, enquanto que os provindos de ambientes familiares mais abastados, em que os pais incentivam a leitura, podem reforçar ainda mais seus interesses nessa prática.

Segundo Eliana Yunes (2016), quem possui uma familiaridade com o imaginário vê melhor a "realidade" e se prepara psiquicamente para os imprevistos, para as "invenções", seja do tipo científico-tecnológico, seja do artístico-ficcional, pois um ou outro dependem de nossa capacidade de ver aqueles vazios e faltas e, demiurgicamente, ir fazendo a ponte, articulando os elos perdidos. O professor, então, enquanto mediador é aquele que elabora

[...] situações novas e estimulantes, bem como promove a criatividade, a curiosidade e o desafio da linguagem simbólica. Se o aluno for capaz de algo mais, o professor mediador indagará formular tarefas novas que potencializem cada individualidade" (TÉBAR, 2011, p. 121). 
Eliane Yunes (2016) enfatiza que ler parece ser uma atividade de sobrevivência, antes que a invenção do alfabeto nos entregasse a escrita como uma maneira de guardarmos a memória das coisas. A estudiosa ressalta que

[...] entender os códigos, o código escrito é desdobrar a condição de estar no mundo sendo mais que um mero decodificador, sendo um sujeito que lê e interpreta o mundo e suas circunstâncias para viver, para agir (YUNES, 2016, p. 22).

Logo, o professor enquanto mediador do aluno com o texto possibilita a realização de reflexões que ultrapassam a decifração da palavra escrita.

Além desses resultados, boa parte dos respondentes alegou que o interesse próprio pela leitura teve papel relevante na sua história de leitor. Isso significa que, talvez, por falta de mediadores e, também, quem sabe, por necessidade no trabalho, na escola ou até mesmo na vida, esses sujeitos precisaram, por eles próprios, perceber a importância da leitura.

Outros respondentes apontaram aquisição de conhecimento, curiosidade, gosto, incentivo devido a outro curso, fuga da realidade, compreensão de si e do mundo, superar perdas de entes queridos, viajar por mundos desconhecidos, passar o tempo no transporte até a universidade, etc. Isso chama atenção pelas várias possibilidades que a leitura propicia, ou seja, esses leitores se dão conta do poder transformador do ato de ler ou o fazem por pura e mera distração.
Outro resultado relevante mostrou que 30 acadêmicos apontaram a internet, a televisão, filmes, blogs, sites ou obras como Harry Potter, Jogos vorazes e O pequeno príncipe como dispositivos que os despertaram para o ato de ler. Logo, notamos que as mídias digitais também podem exercer um papel de influenciadoras no que diz respeito à leitura, dividindo, então, esse papel com a família, a escola, a biblioteca, os professores e até mesmo com o próprio livro.

Podemos citar como exemplo o livro Dois irmãos, de Milton Hatoum (2000), publicado pela editora Companhia das Letras e vencedor do prêmio Jabuti como melhor romance em 2001. Antes de ser anunciada a adaptação da obra para minissérie da TV Globo, os exemplares vendidos não passavam de 60 por semana, conforme a Publishnews, com base nas informações do Bookscan, ferramenta da Nielsen, que monitora o varejo de livros no Brasil. Após o anúncio e a minissérie ir ao ar em 2017, as vendas foram aumentando progressivamente chegando a 1.060 unidades vendidas.

O jornal on-line O Globo (2019), por Ana Clara Veloso, noticiou que a busca por livros citados em Bom Sucesso, novela das 19 horas da Rede Globo (20192020), cresceu em 15\%. O livro campeão nas buscas foi $O$ mágico de $O z$. Karina Matias (2020), no site F5 Folha Uol, mostrou que um levantamento realizado pelo Google apontou um aumento nas 
buscas pelas seguintes obras mencionadas no folhetim: A letra escarlate, de Nathaniel Hawthorne, A morte da porta estandarte, de Aníbal Machado, com um crescimento de $5.000 \%$ na plataforma, e clássicos mais famosos como Dom Casmurro, de Machado de Assis, com um crescimento de $125 \%$. Assim, notamos a forte interferência que a televisão e as mídias digitais exercem sobre as pessoas, chegando ao ponto de influenciá-los na sua formação leitora. Portanto, esses suportes podem ser aliados importantes na difusão da leitura.

Outros artefatos de promoção da leitura que vêm se formando na internet como o booktubers e o Skoob se tornam importantes meios de disseminação de livros. Os booktubers são jovens leitores que compartilham na internet suas impressões sobre os livros que leem por meio de um formato audiovisual: um vídeo que eles mesmos gravam e publicam no YouTube. Esse vídeo geralmente é gravado num ambiente privado, como o quarto, e apresenta atmosfera de leitura: estante de livros, o livro a ser discutido está sempre à mão do influenciador digital, etc.

Conforme Fabiane Burlamaque e Deisi Zanatta (2016, p. 223),

[...] a importância dos booktubers e dos clubes de leitura que vêm se formando na rede está em evidência, pois compreendem que a mediação da leitura, pressupõe a formação do leitor.
Com isso, esse contato está transformando a relação dos jovens com a leitura, mas principalmente entre os livros, a internet e a mediação de leitura, uma vez que tais mediadores se materializam no cotidiano desses leitores e influenciam nas opiniões dos sujeitos.

Outro aparato digital que está ganhando força entre os leitores na contemporaneidade é o Skoob, um site criado em 2009 por Lindenberg Moreira e considerado a maior comunidade de leitores. No site, os usuários, leitores ou skoobers, como são denominados, podem obter seguidores e compartilhar leituras, trocar ideias, comentários, trechos e críticas das obras lidas, além de trocarem dicas sobre livros, através das ferramentas propiciadas pelo site.

De acordo com Rejane Pivetta de Oliveira (2015, p. 74):

O diferencial do Skoob é que se trata de uma comunidade brasileira, que fala a mesma língua, manifestando seus gostos literários, mais ou menos modelados pelo sistema social em que se dão as práticas de produção, circulação e recepção daquilo que todos entendem como literatura. O gosto literário funciona como elemento de agregação e estabelecimento de vínculos entre os usuários da rede, pertencentes a um território comum de trocas e relações sociais.

Logo, o Skoob se torna um espaço de mediação de leitura, isto é, um lugar em que os leitores dialogam e trocam ideias sobre as obras lidas e, assim, ampliam o conhecimento sobre o mundo que a leitura proporciona. De acordo com 
Pedro Barth e Fabiane Burlamaque (2015), este ambiente digital propicia pensar num novo redimensionamento da leitura, especialmente da leitura da literatura. Assim,

[...] uma vez que reconhecemos o potencial do Skoob para o desenvolvimento do letramento digital e literário, faz-se necessário integrá-lo em práticas, projetos ou mediações (BARTH; BURLAMAQUE, 2015, p. 66).

Conforme Chartier (1999), observar as redes de práticas e as regras de leituras próprias às diversas comunidades de leitores é uma primeira tarefa para se chegar a uma história da leitura preocupada em compreender, nas suas diferenças, a figura paradigmática desse leitor que é um furtivo caçador. Dessa forma, alguns aparatos digitais que estão ganhando a atenção dos jovens leitores se tornam espaços para novas relações sociais a partir de uma atividade em comum: a leitura.

Vale mencionar que, além dessa teia virtual, há também uma rede real de troca de experiências sobre as leituras que os jovens realizam. No ambiente escolar ou em encontros privados, a indicação de livros bem como de adaptações de filmes e séries destes, além da troca de comentários sobre "o que gostaram ou não" nos textos, tornou-se um hábito comum entre tais leitores. Conforme Chantal Horellou-Lafarge e Monique Segré (2010, p. 126-127):
A prática da leitura das crianças e adolescentes faz parte de uma relação de amizade, convivência. Os adolescentes têm o costume de transmitir entre si, oralmente, o conteúdo dos livros que lhes interessaram, falam do que leram, estimulam os colegas a compartilhar suas leituras para comunicar suas impressões, para compará-las, verificar o que compreenderam. Evocam suas leituras entre si, trocam e aconselham livros. Muitas vezes, os adolescentes praticam a leitura coletiva, leem em conjunto uma mesma história em quadrinhos, leitura acompanhada de comentários, de reflexões, de brincadeiras.

Assim, percebemos que há uma relação real e virtual de leitores e que o conteúdo dos livros passou a ser assunto de discussão em rodas de conversa e, através disso, alicerça uma relação de existência e de conhecimento. Ocorre uma identificação desses jovens com a leitura, que, consequentemente, passa para o mundo real atingindo uns aos outros, ou seja, a ligação entre eles também passa a se estreitar devido às preferências de leitura e às vivências que isso pode lhes proporcionar.

Dando continuidade ao estudo dos resultados obtidos na pesquisa do Procad, em relação aos sujeitos que alegaram terem sido direcionados para o hábito de ler por meio de livros como Harry Potter e Jogos Vorazes, podemos inferir que o universo ficcional presente nesses textos os tenham influenciado a expandir suas leituras, propiciando, então, uma ampliação na bagagem leitora. A literatura infantil e juvenil, de certa forma, representa o meio em que essas crianças 
e jovens vivem, podendo fazer com que elas se identifiquem com as obras lidas. Logo:

A exploração de temas complexos, perigosos e polêmicos como a repressão governamental, a fome, lutas e a morte vêm se destacando na produção literária contemporânea. Alguns desses motes já foram muito explorados nos contos de fadas e, talvez, de todos eles a morte seja o mais difícil de ser superado. Jogos Vorazes nos apresenta crianças e adolescentes que são forçados a entrar numa arena e matar uns aos outros, restando apenas um sobrevivente (ZANATTA; BURLAMAQUE, 2014, p. 143).

Pela citação supracitada, percebemos a importância que a leitura da literatura pode ter na vida das pessoas, pois essas buscam, por meio das temáticas desses textos, respostas para determinados conflitos pessoais e sociais. Assim, a ficção propicia ao leitor que ele se enxergue na narrativa e possa vir a se identificar com os acontecimentos que rondam as personagens da história.

Conforme Vincent Jouve (2002), o charme da leitura provém em grande parte das emoções que ela suscita. Tal estudioso menciona que, se a recepção do texto recorrer às capacidades reflexivas do leitor, pode influir sobre sua afetividade. Sendo assim, as emoções estão de fato na base do princípio de identificação, motor essencial da leitura de ficção, isso porque elas provocam em nós, como leitores, admiração, piedade, riso ou simpatia, vindas das personagens romanescas que despertam o nosso inte- resse. Dessa forma, a leitura se relaciona também com a subjetividade do leitor.

No que diz respeito à série Harry Potter, ao discutir a questão do leitor em tal obra, Ana Cláudia Munari Pelisoli (2011, p. 17) enuncia que, com base na teoria do efeito proposto por Wolfgang Iser, "é possível buscar o leitor dentro do próprio texto por meio de exames das estruturas que condicionam a sua participação, os lugares vazios, que, aqui, julgamos ser uma das razões principais que tornam a série de Rowling esse fenômeno de leitura". A estudiosa ainda enfatiza que a cultura jovem sempre esteve aliada a um movimento de transgressão, um impulso para o rompimento com a cultura vigente, para criar tendências e estilos com os quais a juventude pudesse se identificar - assim foi com o rock, a onda hippie, o punk, o grunge.

Vera Teixeira Aguiar (2005), por sua vez, realizou um estudo com dez crianças, estudantes de 10 a 13 anos, e cinco adultos, com nível universitário de 30 a 50 anos, sendo todos leitores da obra Harry Potter. O intuito foi observar os movimentos dos sujeitos em direção ao livro, as causas que os levaram à leitura. Os entrevistados ressaltaram que a curiosidade diante da repercussão da obra foi o estopim inicial para lerem o livro. Mas essa curiosidade não proveio dos meios de comunicação, sites, etc., mas, sim, de comentários de pessoas próximas e notícias de publicação da obra. 
Os sujeitos dessa pesquisa também mencionaram que comentam a repercussão da obra e de seu sucesso e a referência a fatos do enredo e de personagens com amigos, colegas de escola e conhecidos. Outros fatores também influenciaram na leitura, como: ver outros jovens lendo e dando gargalhadas, andando sempre com o livro na mochila; compra do livro por parte da mãe; necessidade de atualização, no caso do professor. Uma informação que chama a atenção revela que foi unânime o apontamento de que a fantasia é o elemento mais atraente na leitura. Conforme Aguiar (2005, p. 19-20):

Os livros transmitem a idéia de que, malgrado nossas dificuldades, sempre podemos vencer os obstáculos porque possuímos qualidades inatas, potencialidades a serem desenvolvidas e talentos a serem revelados. Nesse sentido, a coleção funciona com um conto de fadas moderno, para o qual os problemas existem, mas seguramente podem ser resolvidos. A mensagem otimista de mundo que transmite atinge as crianças e os adultos, sobretudo porque a injustiça, a violência, a guerra, a disputa e o ódio não são banalizados, como no dia-a-dia contemporâneo. Ao contrário, todos os males são importantes e devem ser enfrentados e resolvidos.

Se as relações familiares em casa são tumultuadas para Harry Potter, o mesmo acontece no ambiente escolar. E ali, novamente, estamos diante de situações do mundo real, com professores e alunos, diretores e funcionários, salas de aula e campos de esporte. $\mathrm{O}$ prédio da escola é o mundo lá fora, no qual o herói deve penetrar para fazer sua iniciação. Por isso, todas as resistências da família resultam vãs, isto é, quando é chegado o momento, nada impede sua entrada no novo.
Entendemos que a fantasia presente no texto permite ao leitor justamente evadir-se do mundo real e adentrar num mundo imaginário. Ao mesmo tempo, o receptor consegue se enxergar na obra diante das situações vividas pelas personagens, especialmente, pelo protagonista. Logo, entendemos que todos os elementos presentes no enredo visam a contribuir para que o leitor compreenda as etapas de maturidade que precisa passar para atingir a idade adulta, bem como sua relação com o espaço e com os seres com os quais convive.

Maria Lucia Bandeira Vargas (2005) postula que o protagonista de tal obra pode ser percebido como um menino passível de existência verdadeira e, com isso, J. K. Rowling oferece a todos os leitores que trazem viva a memória de sua luta interna pela diferenciação e construção de identidade uma oportunidade para rememorar, através de metáforas riquíssimas, passagens fundamentais para a vida adulta. Vargas (2005, p. 207) enfatiza que:

[...] o encantamento de pessoas de todas as idades pela série de livros Harry Potter parece dever-se, pelo menos parcialmente, à saga do personagem como metáfora do crescimento, do enfrentamento da dor e da superação de si mesmo na busca pela felicidade. Esses são temas comuns a todos, mesmo àqueles que já atravessaram o período crítico do crescimento físico e afetivo, pois o próprio movimento interminável que significa estar vivo nos cerca de rituais de passagem que simbolizam o sempre o nosso renovado encontro e enfrentamento com a nossa intimidade e as sombras que esta projeta. 
Entendemos, diante dos apontamentos apresentados, que a obra Harry Potter instaura uma nova identidade entre os leitores, que vem a ser elaborada a partir da possível identificação com as situações presentes no texto e das vivências das personagens. A escolha e a aceitabilidade por tal obra por muitos leitores, incluindo os respondentes da pesquisa do Procad e os usuários da comunidade do Skoob, bem como demais receptores das mais variadas idades, contrariam a crítica negativa ao livro elaborada por alguns pensadores. Assim, "talvez a magia desses livros esteja no acesso a 'segredos' desconhecidos e na identificação com as necessidades do adolescente, ou no compartilhamento dessa experiência e na troca de opiniões, descobertas, angústias e superações" (FAILLA, 2014, p. 81). Provavelmente, o leitor de tal obra consegue se enxergar no texto e, através dos acontecimentos do enredo, buscar soluções para os percalços da vida, identificação esta que, provavelmente, não encontra ainda na leitura dos clássicos. Com isso, a aceitabilidade dessa saga por parte do público leitor contraria a crítica literária tradicional.

Em uma entrevista ao jornal Folha de São Paulo, para Rodrigo Moura (2003), o crítico literário Harold Bloom afirma que a popularidade de Harry Potter é desesperante. A crítica de Harold Bloom acerca da obra Harry Potter se dá, certamente, devido ao fato de esta, bem como outros textos da cultura de massa, estar ganhando espaço nas mãos dos jovens leitores contemporâneos. Para Bloom, esses livros ocupam o lugar que deveria ser da literatura clássica, ou seja, as obras preferidas dos sujeitos respondentes dessas pesquisas se referem aos textos que a crítica e até mesmo a escola não consideram como leitura legítima. Com isso, entendemos que a cultura erudita somente considera a leitura da literatura, mas as pesquisas mencionadas apontam que o leitor contemporâneo está em contato com leituras um pouco distantes das tradicionais.

De acordo com Italo Calvino (1993), para poder ler os clássicos, é preciso definir de onde eles estão sendo lidos, caso contrário, o livro e o leitor se perdem numa nuvem atemporal. Dessa forma, o rendimento máximo da leitura dos clássicos ocorre para aquele que sabe alterná-la com a leitura de atualidades numa sábia dosagem. Podemos ressaltar que se faz necessário apresentar o texto clássico, mas não desconsiderar os outros escritos que se encontram nas mãos dos leitores. Quem sabe seja possível realizar cotejos entre as obras eruditas e as contemporâneas, a fim de que os estudantes percebam as relações existentes de um conteúdo para o outro e, com o tempo, tornem-se leitores dos escritos eruditos.

Já a obra $O$ pequeno príncipe conquistou os sujeitos respondentes da pesquisa do Procad, certamente, devido às suas 
temáticas, como amizade, solidariedade e desapego. No Brasil, tal obra ficou conhecida como o livro das misses, porque as moças que participavam de concursos de beleza o mencionavam como texto favorito. Por volta de 1980, o livro chegou a entrar na lista de autoajuda, pois indicava fórmulas para as pessoas terem sucesso no trabalho, por exemplo. Contudo, para alguns estudiosos entrevistados por Gabriela Romeu (2013) para a Folha UOL, a obra é, sim, literatura.

Segundo Ana Maria Machado (2013), o autor não pretendia dar conselhos a ninguém, mas, sim, realizar reflexões filosóficas. Heloisa Prieto (2013), por sua vez, enfatiza que a obra mescla preceitos arcaicos a um cenário de ficção científica, daí vem sua originalidade literária, além de tratar-se de um texto que desafia categorias como autoajuda, literatura infantil e juvenil e, só por isso, merece ser lido.

Para Marisa Lajolo (2013), O pequeno príncipe pode ser considerado literatura, porque se trata de ficção, invenção de situações imaginárias passíveis de serem compartilhadas por muita gente. Já Paulo Werneck (2013) ressalta que toda obra literária possui um pouco de autoajuda e que, de tão bonitas, bem escritas e verdadeiras, sempre têm algo a ensinar e a ajudar a nos tornarmos pessoas melhores. Conforme Roger Mello (2013), a obra dá ao delírio o verdadeiro poder de poesia. Assim, quem sabe, os acadêmicos que alegaram tomar gosto pela leitura por meio de tal obra tenham encontrado nela experiências estéticas a ponto de compreenderem determinados acontecimentos da vida.

Em uma consulta à comunidade do Skoob em 05 de abril de 2015, Rejane Pivetta de Oliveira apurou que, entre os dez títulos preferidos do público leitor, encontravam-se os seguintes: $1^{\circ}$ A menina que roubava livros; $2^{\circ}$ A culpa é das estrelas; $3^{\circ}$ Harry Potter e as relíquias da morte; $4^{\circ}$ Harry Potter e a pedra filosofal; $5^{\circ}$ Harry Potter e o prisioneiro de Azkaban; $6^{\circ}$ O pequeno príncipe; $7^{\circ}$ Harry Potter e o enigma do príncipe; $8^{\circ}$ Harry Potter e o cálice de fogo; $9^{\circ}$ Jogos vorazes; $10^{\circ}$ Harry Potter e a Ordem da Fênix.

Notamos que três obras mencionadas pelos respondentes da pesquisa do Procad também estão entre os favoritos mencionados pelos leitores que frequentam o Skoob: Harry Potter, O pequeno príncipe e Jogos vorazes. Entendemos, com isso, que as práticas de leitura vêm se transformando devido a diversos fatores que envolvem o surgimento dos novos suportes, das mídias digitais e dos meios de comunicação. Esses novos aparatos estão influenciando na preferência de leitura e, consequentemente, na formação de tais sujeitos como leitores. Assim,

[...] mudam-se os tempos, transformam-se os leitores, novas tecnologias produzem outros suportes de leitura que, por sua vez, implicam formas diferenciadas de ler e novas concepções para o que seja a leitura" (BALZAN, 2018, p. 22). 
Em relação aos 83 respondentes da pesquisa do Procad que alegaram interesse próprio, aquisição de conhecimento, curiosidade, gosto, incentivo devido a outro curso, fuga da realidade, compreensão de si e do mundo, superar perdas de entes queridos, viajar por mundos desconhecidos, passar o tempo no transporte até a universidade, etc., entendemos que esses sujeitos necessitaram da leitura para auxiliá-los em determinados momentos de suas vidas. O que causa apreensão é que tais sujeitos não tiveram mediadores de leitura, mas por si mesmos buscaram a realização dessa experiência.

Como afirma Petit (2008), é a leitura que faz com que o indivíduo construa sua identidade e que permite também a elaboração de um sentido para seus próprios conflitos e sua realidade. Logo, entendemos que, talvez, algumas situações vivenciadas, bem como a busca por maior informação ou conhecimento, direcionaram os sujeitos na sua busca pela leitura por conta própria.

Dando sequência ao resultado da pesquisa do Procad, dentre o total dos sujeitos, apenas 4 respondentes mencionaram não possuir hábito de ler ou não lembraram algum fato, objeto, sujeito ou espaço que tenha contribuído para a sua formação como leitor. Contudo, é preocupante que 110 acadêmicos não tenham respondido tal questão, o que nos leva a entender que esses sujeitos, provavelmente, não tiveram mediadores de leitura em suas trajetórias de vida, sejam elas na esfera pessoal, escolar ou profissional. Também, podemos inferir que tais acadêmicos não reconhecem terem tido uma história de leitor ou a participação de outros sujeitos nela. Talvez, no que se refere ao âmbito familiar, a condição financeira não possibilitou a aquisição de materiais de leitura, bem como os membros da família não terem sido leitores e, por isso, não transmitirem o gosto pela leitura. Já em relação ao espaço escolar, entendemos que tal ambiente e os profissionais que ali atuam podem não ter incentivado para a prática leitora. Esse resultado é preocupante, uma vez que, como professores, suas práticas no cotidiano escolar se voltarão para o uso da leitura e da escrita.

De acordo com Pennac (1993), a maior parte dos leitores se concede cotidianamente o direito de não ler. Contudo, segundo o estudioso

[...] a idéia de que a leitura humaniza o homem é justa no seu todo, mesmo se ela padece de algumas deprimentes exceções. Tornamo-nos um pouco mais humanos, entenda-se aí por um pouco mais solidários com a espécie [...] (PENNAC, 1993, p. 144).

Assim, cabe aos docentes universitários apresentar uma diversidade de textos aos estudantes de Letras e de Pedagogia, respondentes da pesquisa do 
Procad, para que esses expandam os seus horizontes em relação à leitura.

Com isso, os elementos como algum fato, sujeito, objeto, espaço, prática, experiência ou rotina que tenha sido relevante para a história de leitor dos acadêmicos de Letras e de Pedagogia nos permitem conhecer que a influência e a mediação de leitura podem ser oriundas de várias esferas da sociedade. Mas, atentamos para o fato de boa parte dos respondentes da pesquisa terem mencionado o professor como responsável por transmitir o gosto pela leitura, o que nos faz perceber a relevância desse profissional como formador de leitores.

\section{Considerações finais}

O objetivo deste artigo foi descrever e analisar algum fato, sujeito, objeto, espaço, prática, experiência ou rotina que influenciou na história de leitor de acadêmicos iniciantes em cursos superiores de Letras e de Pedagogia por meio do questionário aplicado no início das atividades acadêmicas de 2015 pelas instituições integrantes do Projeto de Cooperação Acadêmica Interinstitucional (Procad): Universidade Estadual Paulista "Júlio de Mesquita Filho" (Unesp), campi de Assis, de Marília e de Presidente Prudente, da Universidade Federal do Espírito Santo (Ufes) e da Universidade de Passo Fundo (UPF).
Por meio dos resultados, podemos perceber que a mediação de leitura provém de várias esferas, ou seja, a família e o professor dividem tal função com outros elementos, como a internet. Mesmo que haja outros influenciadores de leitura, entendemos que a tarefa do professor se circunscreve a inserir o aluno no mundo da leitura, prática responsável pela construção do pensamento crítico.

Ao analisarmos as grades curriculares dos cursos de Letras e de Pedagogia das universidades que participaram do Procad, deparamo-nos com o rol de disciplinas ofertadas por tais cursos. A grade curricular do curso de Letras da Unesp, campus de Assis, oferece disciplinas clássicas, ou seja, voltadas para o estudo da teoria, de literaturas específicas e línguas estrangeiras. A estrutura curricular dos cursos de Pedagogia da Unesp, campus de Marília, não oferta nenhuma disciplina referente ao estudo do livro e da leitura. Algo similar acontece no curso de Pedagogia do campus de Presidente Prudente, com exceção da disciplina de Literatura infantil, que consta na grade curricular, devendo ser cursada no terceiro ano da graduação tanto do período matutino quanto vespertino.

Em relação à grade curricular do curso de Letras da Ufes, percebemos que a matriz do curso tanto matutino quanto vespertino apresenta um rol das disciplinas obrigatórias e optativas, matérias voltadas para a área da literatura, o que 
nos faz entender que o objeto de estudo seja o texto literário. Com isso, orientados por esse documento, notamos que, talvez, seja preciso inserir o estudo dos demais gêneros textuais que se fazem presentes na sociedade. Em relação à grade curricular do curso de Pedagogia da Ufes, foi possível perceber que a situação é a mesma encontrada na matriz do curso de Pedagogia da Unesp, campus de Marília, ou seja, não é ofertada nenhuma disciplina que aborde o estudo da leitura especificamente.

Tal documento do curso de Letras Português/Inglês e Português/Espanhol da UPF apresenta uma estrutura que dá ênfase ao estudo da leitura, contemplando os diversos gêneros e tipos textuais. Assim, tal licenciatura possibilita um estudo mais profundo e específico de cada gênero textual, seja literário ou não. Fica evidente a presença de disciplinas que contemplam o estudo do texto ao longo do curso, viabilizando o contato constante dos graduandos com a leitura durante toda a formação acadêmica.

A grade curricular do curso de Pedagogia da UPF também oferta disciplinas que se voltam para o estudo da leitura. Ao analisarmos esse documento, notamos que, no primeiro semestre, consta a matéria de Leitura e produção de textos e, no oitavo, aparece Literatura infantil e juvenil e teatro na escola. Podemos perceber que, embora tal graduação contemple disciplinas que envolvam a leitura, somente no primeiro e no último semestre elas são efetivamente desenvolvidas. Logo, no decorrer da formação, fica uma lacuna no que diz respeito à leitura.

Posto isso, enfatizamos que os docentes universitários dos cursos de Letras e de Pedagogia das instituições do Procad, dentro do rol de disciplinas ofertadas, necessitam repensar as práticas leitoras, direcionando esses futuros professores a percorrerem caminhos para novas leituras. Tais questões nos levam a entender que $o$ ato de ler, no momento em que se converte num exercício prazeroso, possibilitará uma maior liberdade de sua própria ação, conseguindo efetivamente envolver o sujeito e torná-lo leitor. Com isso, expandir essa atividade para as salas de aula.

Na nossa ótica, o docente é um agente importante em transmitir o gosto pela leitura, mas, para que isso aconteça, precisa ser submetido durante a sua formação inicial a tal prática. Seu papel se circunscreve ao de profissional transformador, isto é, aquele que, por meio da leitura, consiga formar pessoas capazes de refletir, criticar, agir e transformar o mundo em que vivem. 


\section{Reading in undergraduate: the history of reader of university students}

\section{Abstract}

Reading should be worry in all areas of knowledge, however future teachers of Letters and Pedagogy will work with questions that involve the interpretation and formation of critical thinking of their students. Therefore, in this text, we aim to describe and analyze some fact, subject, object, space, practice, experience or routine that influenced in the history of readers of beginning academics in undergraduate in Letters and Pedagogy at three Brazilian universities. This article is the result of research developed at the University of Passo Fundo (UPF), from 2015 to 2019, which originated from an Interinstitutional Academic Cooperation Project (Procad), whose member institutions were: Paulista State University "Júlio de Mesquita Filho" (Unesp), university campi of Assis, of Marília and of Presidente Prudente, Federal University of Espírito Santo (Ufes) and UPF. The analysis of the research result showed that several elements such as books, spaces, digital media and subjects such as father, mother, brother, teacher, friend were part of the reader history of the research students participated. Therefore, knowing this context of reading of students of Letters and Pedagogy of the institutions that participated in Procad becomes relevant to make of aware of university teachers in these degrees to the need to improve reading practices during the initial training of these students, future teachers.

Keywords: Reading in undergraduate of Letters and Pedagogy. Reader story. Initial teacher training. Teacher-mediator.

\section{Nota}

1 “[...] la lectura es um arte que se transmite más que enseñarse”.

\section{Referências}

AGUIAR, V. T. O bruxo e os leitores. In: RETTENMAIER, M.; JACOBY, S. Além da plataforma nove e meia: pensando o fenômeno Harry Potter. Passo Fundo: UPF, 2005. p. 11-22.

ANTUNES, C. Como desenvolver as competências em sala de aula. Petrópolis, RJ: Vozes, 2001.

BALADELI, A. P. D.; BARROS, M. S. F.; ALTOÉ, A. Desafios para o professor na sociedade da informação. Educar em Revista, Curitiba, v. 28, n. 45, p. 155-156, jul./set. 2012. Disponível em: http//scielo.br/pdf/er/ n45/11.pdf. Acesso em: 20 maio 2018.

BALZAN, C. F. P. Da leitura prática às práticas de leitura: o caso dos cursos superiores de tecnologia. 271 p. Tese (Doutorado em Letras) - Universidade de Caxias do Sul, Caxias do Sul, 2018.

BARTH, P. A.; BURLAMAQUE, F. V. Redes sociais e o ensino: o skoob como ferramenta para o letramento digital e literário. $\mathrm{Nu}$ ances: Estudos sobre Educação, Presidente Prudente, v. 26, n. 3, p. 53-73, set./dez. 2015.

BURLAMAQUE, F. V.; ZANATTA, D. L. Os booktubers e a formação de leitores. In: MARTHA, A. Á. P.; AGUIAR, V. T. de (org.). Entre livros e leitores: escritos vários. São Paulo: Cultura Acadêmica; Assis: ANEP, 2016. p. 207-226.

CALVINO, I. Por que ler os clássicos. Trad. Nilson Moulin. São Paulo: Companhia das Letras, 1993.

CAMPOS, M. I. B. Ensinar o prazer de ler. São Paulo: Editora Olho D’Água, 1999. 
CHARTIER, R. A aventura do livro: do leitor ao navegador - conversações com Jean Lebrun. Trad. Reginaldo Carmello Corrêa de Moraes. São Paulo: Editora Unesp, 1998.

CHARTIER, R. A ordem dos livros: leitores, autores e biblioteca na Europa entre os séculos XIV e XVIII. Brasília: Editora Universidade de Brasília, 1999.

FAILLA, Z. Retratos de um jovem leitor. Revista Observatório Itaú Cultural, São Paulo, n. 17, p. 76-94, ago./dez. 2014. Disponível em: http://www.itaucultural.org.br/secoes/observatorio-itau-cultural/revista-observatorio. Acesso em: 10 mar. 2018.

FREIRE, P. A pedagogia da autonomia. São Paulo: Paz e Terra, 1999.

FREIRE, P. A importância do ato de ler: em três artigos que se completam. 47. ed. São Paulo: Cortez, 2006.

HATOUM, Milton. Dois irmãos. São Paulo: Companhia das Letras, 2000.

HAUSER, A. Sociología del publico. In: HAUSER, A. Sociología del arte. Barcelona: Guadarrama, 1977.

HORELLOU-LAFARGE, C.; SEGRÉ, M. Sociologia da leitura. Trad. Mauro Gama. Cotia, SP: Ateliê Editorial, 2010.

JOUVE, V. A leitura. Trad. Brigitte Hervor. São Paulo: Editora Unesp, 2002.

LAHIRE, B. Sucesso escolar nos meios populares: as razões do improvável. Trad. Ramon Américo Vasques e Sonia Goldfeder. São Paulo: Ática, 1997.

LAJOLO, M. O pequeno príncipe é literatura ou autoajuda? In: ROMEU, G. Saiba por que o pequeno príncipe é considerado o livro das misses. 2013. Disponível em: https://www1.folha.uol.com.br/ folhinha/2013/04/1269200-saiba-por-que-o-pequeno-principe-tem-apelido-de-livro-de-miss.shtml. Acesso em: 22 ago. 2018.

LAJOLO, M.; ZILBERMAN, R. A formação da leitura no Brasil. São Paulo: Ática, 2003.
MACHADO, A. M. O pequeno príncipe é literatura ou autoajuda? In: ROMEU, G. Saiba por que o pequeno príncipe é considerado o livro das misses. 2013. Disponível em: https://www1.folha.uol.com.br/ folhinha/2013/04/1269200-saiba-por-que-o-pequeno-principe-tem-apelido-de-livro-de-miss.shtml. Acesso em: 22 ago. 2018.

MATIAS, K. Bom Sucesso conquista público e incentiva leitura ao falar de forma lúdica de obras clássicas. F5 Uol, São Paulo, 19 jan. 2020. Disponível em: https://f5.folha. uol.com.br/televisao/2020/01/bom-sucesso-conquista-publico-e-incentiva-leitura-ao-falar-de-forma-ludica-de-obras-classicas. shtml. Acesso em: 20 jan. 2020.

MELLO, R. O pequeno príncipe é literatura ou autoajuda? In: ROMEU, G. Saiba por que o pequeno príncipe é considerado o livro das misses. 2013. Disponível em: https://www1.folha.uol.com.br/ folhinha/2013/04/1269200-saiba-por-que-o-pequeno-principe-tem-apelido-de-livro-de-miss.shtml. Acesso em: 22 ago. 2018.

MÉKIS, C. A biblioteca escolar CRA e a leitura se transformam em espaços de aprendizagem: observando o planeta biblioteca escolar desde as alturas e as diferentes rotas pedagógicas. In: RÖSING, T. M.; FERRARI, C. F. (org.). Biblioteca, inovação e comunidades leitoras. Passo Fundo: Ed. Universidade de Passo Fundo, 2016. p. 173-190.

MOTOYAMA, J. F. M.; SANTOS, I. D.; SILVA, G. G. Mediadores para além do ambiente escolar: o que nos dizem acadêmicos de Pedagogia e Letras. In: FEBA, B. L. T.; SOUZA, R. J. (org.). Mediação de leitura: espaços e perspectivas na formação docente. Tubarão: Gráfica e Editora Copiart, 2017. p. 12-44.

MOURA, R. Crítico diz que popularidade de Harry Potter é “desesperante”. Folha de São Paulo, São Paulo, 25 jan. 2003. Disponível em: https:/www1.folha.uol.com.br/folha/ ilustrada/ult90u30244.shtml. Acesso em: 10 ago. 2018. 
O GLOBO. Venda do livro "Dois irmãos" dispara após anúncio da minissérie na TV. O Globo, São Paulo, 17 jan. 2017. Disponível em: http//oglobo.globo.com/cultura/livros/ venda-do-livro-dois-irmaos-dispara-apos-anuncio-da-minisserie-na-tv-20775630. Acesso em: 20 fev. 2018.

OLIVEIRA, R. P. Favoritos do público: uma análise das práticas de leitura da comunidade virtual do Skoob. Desenredo, Passo Fundo, v. 11, n. 1, p. 70-91, jan./jun. 2015. Disponível em: http://seer.upf.br/index.php/rd/article/ view/4968/3443. Acesso em: 15 abr. 2018.

PELISOLI, A. C. M. D. Do leitor invisível ao hiperleitor: uma teoria a partir de Harry Potter. 263 p. Tese (Doutorado em Letras) - Pontifícia Universidade Católica do Rio Grande do Sul, Porto Alegre, 2011.

PENNAC, D. Como um romance. Trad. Leny Werneck. Rio de Janeiro: Rocco, 1993.

PEROZIM, L. Precisamos ir além da narrativa. Entrevista com Ezequiel Theodoro da Silva. Observatório Educacional, Forumped, RJ: 2009. Disponível em: http://observatorio-educacional.blogspot.com/2009/05/precisamos-ir-alem-da-narrativa.html. Acesso em: 30 jun. 2018.

PERRENOUD, P. Formar professores em contextos sociais em mudança: prática reflexiva e participação crítica. Revista Brasileira de Educação, n. 12, p. 5-21, set./dez. 1999. Disponível em: https://www.unige.ch/ fapse/SSE/teachers/perrenoud/php_main/ php_1999/1999_34.html. Acesso em: 30 abr. 2018.

PETIT, M. Una arte que se transmite. Desenredo, Passo Fundo, v. 2, n. 1, 99-16, jan./ jun. 2006.

PETIT, M. Os jovens e a leitura. Trad. Celina Olga de Souza. São Paulo: Editora 34, 2008.

PETIT, Michèle. Leituras: do espaço íntimo ao espaço público. Trad. Celina Olga de Souza. São Paulo: Editora 34, 2013.
PRIETO, H. O pequeno príncipe é literatura ou autoajuda? In: ROMEU, G. Saiba por que o pequeno príncipe é considerado o livro das misses. 2013. Disponível em: https://www1.folha.uol.com.br/ folhinha/2013/04/1269200-saiba-por-que-o-pequeno-principe-tem-apelido-de-livro-de-miss.shtml. Acesso em: 22 ago. 2018.

ROCHA, A. Formação de mediadores de leitura: o sentido entre o texto e o seu leitor. Ilustrações Bruno Palma e Silva. Curitiba: Hum Publicações, 2016.

ROMEU, G. Saiba por que o Pequeno Príncipe tem apelido de livro de miss. Folha de São Paulo, São Paulo, 27 abr. 2013. Disponível em: http://www1.folha.uol.com.br/ folhinha/2013/04/1269200-saiba-por-que-opequeno-principe-tem-apelido-de-livro-demiss.shtml. Acesso em: 22 set. 2018.

SILVA, R. J. Formar leitores na escola. In: SILVA, R. J.; BORTOLIN, S. Fazeres cotidianos na biblioteca escolar. São Paulo: Polis, 2006. p. 73-96.

TÉBAR, L. O perfil do professor mediador: pedagogia da mediação. Trad. Priscila Pereira Mota. São Paulo: Editora Senac São Paulo, 2011.

VARGAS, M. L. B. Crescimento e busca da identidade em Harry Potter. In: RETTENMAIER, M.; JACOBY, S. Além da plataforma nove e meia: pensando o fenômeno Harry Potter. Passo Fundo: UPF, 2005. p. 193-207.

VELOSO, A. C. Bom sucesso: buscas por livros citados em novela crescem até $15 \%$. O Globo, São Paulo, 29 out. 2019. Disponível em: https://oglobo.globo.com/cultura/revista-da-tv/bom-sucesso-buscas-por-livros-citados-em-novela-crescem-ate-15-24048328. Acesso em: $10 \mathrm{dez} .2019$.

WERNECK, P. O pequeno príncipe é literatura ou autoajuda? In: ROMEU, G. Saiba por que o pequeno príncipe é considerado o livro das misses. 2013. Disponível em: https://www1.folha.uol.com.br/ folhinha/2013/04/1269200-saiba-por-que-o- 
-pequeno-principe-tem-apelido-de-livro-de-miss.shtml. Acesso em: 22. Ago. 2018.

YUBERO, S.; LARRAÑAGA, E.; CERRILLO, P. El valor de la lectura em la formación Del hábito lector de los Estudiantes universitarios. In: NÚNEZ, E. M.; RÖSING, T. (org.). Prácticas de lectura y escrita. Passo Fundo: Editora da Universidade de Passo Fundo, 2009. p. 115-136.

YUNES, E. Professor leitor: uma aprendizagem e seus prazeres. Ilustrações Bruno Palma e Silva. Curitiba: Hum Publicações, 2016.

ZANATTA, D. L.; BURLAMAQUE, F. V. O jovem e as narrativas contemporâneas: uma análise de Jogos Vorazes. In: AGUIAR, V. T.; MARTHA, A. Á. P. (org.). Literatura infantil e juvenil: leituras plurais. São Paulo: Cultura Acadêmica, 2014. p. 141-152.

ZILBERMAN, R.; SILVA, E. T. Pedagogia da leitura: movimento e história. In: ZILBERMAN, R.; SILVA, E. T. (org.). Leitura: perspectivas interdisciplinares. São Paulo: Ática, 1991. p. 111-115. 